HORTICULTURE

\title{
Anti-Nutritional Factor of Vegetables and their Effect on Human Body- A Review
}

\author{
Ratan Das ${ }^{* 1}$, Debashish Sen ${ }^{2}$ and Tapas Paul ${ }^{3}$ \\ ${ }^{1}$ Department of Horticulture and Postharvest Technology, Institute of Agriculture, Visva-Bharati, Sriniketan-731 236, WB, India \\ ${ }^{2}$ College of Agriculture Tripura, Lembucherra- 799210, West Tripura, India \\ ${ }^{3}$ Department of Genetics \& Plant Breeding and Crop Physiology, Institute of Agriculture, Visva-Bharati, Sriniketan- 731 236, WB, \\ India
}

*Corresponding author: ratandasiihr@gmail.com (ORCID ID: 0000-0001-6440-7190)

Paper No. 785

Received: 13-04-2019

Revised: 16-07-2019

Accepted: 22-08-2019

\begin{abstract}
Vegetables are well known for their nutritional and medicinal property but some of them contain certain components that are not desirable for human consumption. They are designated as anti-nutritional factors. Plant essentially use these compound as defense mechanisms against Herbivorous, insect pest, pathogens, etc., however, many of them are likely to the human being on consumption. Many popular vegetables cope like tomato, potato, spinach contain toxic compounds capable of apoptosis. Some are again neurotoxin like Choline-esterase inhibitor in pumpkin. Few vegetables even contain $\mathrm{HCN}$ which is capable to block the ATP synthesis. In this review, the major anti-nutritional factor in the vegetables and their impact on the body is being discussed.

Highlights

( Vegetables are rich source of vitamin and minarils but many of them also contain antinutrational factor like Saponins, Trypsin inhibitors, HCN etc.

( Many important vegetable like tomato, potato, Spinach contains tomatine, Solanine, Saponins respectively and have adverce effect on cell growth and development.
\end{abstract}

Keywords: Anti- nutritional factor, vegetable, neurotoxin and Choline-esterase inhibitor

Vegetables are widely known as "protective foods" due to their diverse health benefits. They are rich in vitamins, minerals, essential fatty acids, amino acids and dietary fiber (Uusiku et al. 2010) and various necessary bioactive compounds. Vegetables are one of the important sources of bioactive compounds collectively termed as phytochemicals which are reported to be essential for sound health (Shukla et al. 2016). However, few of them are very toxic and fatal to humans or animals as a whole when consumed. Those toxic compounds are popularly known as anti-nutritional factor (e.g., oxalates, tannins, nitrate) (Da et al. 2017) They reduce the ability of nutrients such as minerals, vitamins and even proteins within the vegetable and even in the human body. In other words, they affect the nutritional value of the vegetable. Many vegetables contain different kinds of anti-nutritional factors, few of them even neurotoxin. Vegetables like Lima beans (210-310 mg/100g), Cassava (110 mg/100g), Peas $(2.3 \mathrm{mg} / 100 \mathrm{~g})$ contain a considerable high amount of HCN which is very toxic to the animal. On the other hand, Spinach $(750 \mathrm{mg} / 100 \mathrm{~g}$, Beet greens (610 mg/100g), Okra (146 mg/100g), Parsley (100 mg/100g), Leeks (89 mg/100g) contains oxalate which is lethal in higher concentration (Sinha and Vikrant 2017).

Cassava: Though cassava is not very popular in Bharath but it is one of the major crop in Africa and many other counties. It contains a high amount of starch and many other essential nutrients. 
Ironically, it contains an anti-nutritional factor hydrogencyanide $(\mathrm{HCN})$ up to a concentration of $110 \mathrm{mg} / 100 \mathrm{~g}$ which may be released by hydrolysis (Akande et al. 2010). Cassava produces cyanogenic glucosides as a defense to protect itself from herbivore and pathogen attack (Zagrobelny et al. 2004). But it is very toxic to mammals and may kill the individual by disfunction of the central nervous system, respiratory failure and cardiac arrest (D'Mello and Acamovic 1989). Cyanide inhibits cytochrome oxidase in electron transport, hence ATP synthesis blocked. If it may cause to death if consumed in an abundant amount, symptoms include faster and deeper respiration, a faster irregular and weaker pulse, salivation and frothing at the mouth, muscular spasms, dilation of the pupils, and bright red mucous membranes (Bjarnholt and Moller 2008).

Tomato: Lycopersicon esculentum synthesizes a glycoalkaloid, tomatine which known as an antinutritional factor (Chattoo et al. 2011). It generally creates gastric discomfort. But recently it has been reported that it has the capability to kill the cell in higher concentration. The green tomato extracts containing a high amount of tomatine strongly inhibited the human cancer cell lines viz. breast (MCF-7), colon (HT-29), gastric (AGS), and hepatoma (liver) (HepG2), as well as normal human liver cells (Mendel et al. 2009).

Potato: A chemical compound Solanine is predominantly found in the tuber of the potato (Solanum tuberosum L.) (Kodamatani et al. 2005). A higher concentration of this substance is reported in the green peel and also in the sprouts of potato (Korpan, et al. 2004). It is the main toxic compound found in this crop. It is toxic for the animal cell and shows signs of apoptosis. Solanine opens up the PT channels in the membrane by lowering the membrane potential, leading to $\mathrm{Ca}^{2+}$ being transported down its concentration gradient, which in turn leads to the rise of the concentration of $\mathrm{Ca}^{2+}$ in the cell, turning on the mechanism of apoptosis (Gao et al. 2006). Researcher observed that a strong toxic effect on tumor cells (Ji 1995) also an inhibiting effect on the growth of breast cancer cells (Son et al. 2003).

Kidney bean: The legumes are known for trypsin inhibitory activity. A good amount of trypsin inhibitor was detected in Phaseolus vulgaris (Manzoor, et al. 2016). Trypsin inhibitors inhibit the activity of the enzymes trypsin and chymotrypsin in the gut, thus negatively influence the protein digestion. In a prolonged consumption, it may cause protein deficiency in the body. It has been also reported that Trypsin inhibitors losses their activity with an increase in temperature and it completely destroyed in more than $90{ }^{\circ} \mathrm{C}$. raw kidney beans contain anti-vitamin $\mathrm{E}$ that produces necrosis of liver and muscular dystrophy (Sinha and Vikrant 2017).

Broad Bean: Vicia faba L. is considered as one of the nutritious legumes but it reduces the Glucose6-phosphate dehydrogenase deficiency (G6PDD) in the body, as a result, the disease Favism develop. The victims suffer from an inherited biochemical abnormality which affects the metabolism of glutathione in red blood cells and is the result of decreased activity of the enzymes glucose6-phosphate dehydrogenase. In a person with his abnormality, the red cells are more prone to injury and destruction by certain drugs, such as sulphonamide and this raises complications in the treatment of infectious disease (Dmello et al. 1991).

Spinach: spinach is well known for its nutritional value. It a rich source of vitamin and minerals but it also contains an anti-nutritional factor called Saponin (Price et al. 1987). Saponins are water soluble, bitter in taste and have the ability to haemolyse the red blood cells. Based on their chemical nature they can be classified into two major groups i.e. steroidal and triterpenoid saponins. Saponins are capable of disrupting red blood cells and producing diarrhoea and vomiting. Uptake of certain nutrients including glucose also and cholesterol also reduces in the gut through intraluminal physicochemical interaction. It has been proved that Saponins also peruse the antispermal effect (Su et al. 1986 and Pant et al. 1989) and hypocholesterolemic effects (Esenwah et al. 2008).

Taro: Colocasia esculenta is used as a green leafy vegetable and also corm as a source of carbohydrates. The leaf is very nutritious and rich in iron. The plant produces huge foliage (leaves and petioles) yield up to $370 \mathrm{t} / \mathrm{ha} /$ year (Toan et al. 2019). But it contains a good amount of Oxalates both in their leaf and corm. Oxalates are a test less and order less compound. Essentially oxalates bind with calcium and crystallize causing irritation and pain. In savior condition, it may cause inflammation. It can be particularly painful when the crystals 
implant themselves in areas where they prevent other material from passing through (such as in your digestive tract). Additionally, in the case of a permeable or "leaky" gut, a lot of oxalates are absorbed into the body and this overload is linked to several health issues including fibromyalgia, autism, kidney stones etc., calcium oxalate is very deleterious for human nutrition and health, essentially it decreasing calcium absorption and aiding the formation of kidney stones (Noonan et al. 1999). Although, every day we consume oxalates with our food without facing much of complicacy because the effect is concentration dependent. Small doses of oxalate may cause headaches, pain and twitching in muscles, and cramps. A Larger dose can affect the heart leads to an irregular heartbeat, a drop in blood pressure even the signs of heart failure eventually individuals may face a shocklike state, causing convulsions, coma, and possibly death. The lethal dose for an adult is about $70 \mathrm{mg} /$ $\mathrm{kg}$ (Sinha and Vikrant 2017).

Lettuce: It is a well-known salad crop consumed all over the world. Nitrate was reported in the leaf of lettuce which causes many health issues. Nitrate is mainly to be found in cell vacuoles and is xylem transported. Nitrate accumulation can have a serious deleterious effect. Within the gastrointestinal tract, nitrate is reduced to nitrite which is absorbed into the bloodstream where it binds with hemoglobin oxidizing ferrous iron to ferric iron to form methemoglobin. This form of hemoglobin complex is incapable of oxygen transport. The result is Anoxia, specifically referred to as methemoglobinemia.

Winged bean: Psophocarpus tetragonolobus is a minor vegetable crop but in the recent years it has attracted much attention essentially for its protein content. All parts of this plant are edible and high in protein and oil contents. But it contains some anti-nutritional compounds like tannin, phytic acid, trypsin inhibitor, chymotrypsin inhibitor, amylase inhibitor and lectin in various concentrations. Tannin contents ranged from 1.35--6. $75 \mathrm{mg} / \mathrm{g}$ of bean. Phytic acid contents ranged from 7.77$12.03 \mathrm{mg} / \mathrm{g}$ of bean. These compounds express Hemagglutinating activity when consumed row. However, they are thermosensitive and lose their efficiency during cooking (Kotaru et al. 1987).

Pumpkin: Being a nutritious vegetable, it contains
Choline-esterase inhibitor which beliefs to be a neurotoxin (Chattoo et al. 2011). Choline-esterase inhibitor negatively influenced the choline esters which act as neurotransmitters. If the concentration of the Choline-esterase inhibitor increases in the system for a long time, then individuals may suffer from the neurological disorders like Alzheimer's disease.

\section{CONCLUSION}

Vegetables are an important component of nutritional security. It is rich in serial nutrient but it also contains toxic components, even the neurotoxin causing disease like Alzheimer's. Trypsin inhibitor, chymotrypsin inhibitor, amylase inhibitor, ATP synthesis blocker etc., can also be found in various major vegetables. Most of the toxins found in the vegetable are thermosensitive and in a trace amount. So, it is safe to consume after cooking. Row vegetables can also be consumed up to a certain limit. Essentially, it is important to bring variation in our food consumption to avoid the ill effect of the toxic chemical present in our diet.

\section{REFERENCES}

Akande, K.E., Doma, U.D., Agu, H.O. and Adamu, H.M. 2010. Major anti nutritients found in plant protein sources: Their effect on nutrition. Pakistan Journal of Nutrition, 9(8): 827-832.

Bjarnholt, N. and Moller, B.L. 2008. Hydroxynitrile glucosides. Phytochemistry., 69: 1947-1961.

Chattoo, M.A., Khan, S.H., Anjum Ara and Makhdoomi, M.I. 2011. Antinutritional factors in vegetables. Rashtriya Krishi, 6(1): 9-11.

Da Silva Dias, João, C. and Imai, S. 2017. Vegetables consumption and its benefits on diabetes. Journal of Nutritional Therapeutics, 6(1): 1- 10.

Dmello, J.P., Duffus, C.M. and Duffus, J.H. 1991. Toxic substance in crop plants. Cambridge: Royal Society of Chemistry, pp. 339.

D'Mello, J.P.F. and Acamovic, T. 1989. Leucaena leucocephala in poultry nutrition: A review. Anim. Feed Sci. Technol., 26: 1-28.

Esenwah, C.N. and Ikenebomeh, M.J. 2008. Processing effects on the nutritional and anti- nutritional Contents of African Locust Bean (Parkiabiglobosa Benth.) Seed. Pak. J. Nutr., 7(2): 214-217.

Gao, S.Y., Wang, Q.J. and Ji, Y.B. 2006. Effect of solanine on the membrane potential of mitochondria in HepG2 cells and $\left[\mathrm{Ca}_{2}{ }^{+}\right] \mathrm{i}$ in the cells. World J. Gastroenterol., 12(21):3359-3367.

Ji, Y.B. 1995. Pharmacological Action and Application of Available Composition of Traditional Chinese Medicine. 
1st ed. Heilongjiang: Heilongjiang Science and Technology Press, pp. 433.

Kodamatani, H., Saito, K., Niina, N., Yamazaki, S. and Tanaka, Y. 2005. Simple and sensitive method for determination of glycoalkaloids in potato tubers by high-performance liquid chromatography with chemiluminescence detection. J. Chromatogr. A., 1100: 26-31.

Korpan, Y.I., Nazarenko, E.A., Skryshevskaya, I.V., Martelet, C., Jaffrezic-Renault, N. and El'skaya, A.V. 2004. Potato glycoalkaloids: true safety or false sense of security? Trends Biotechnol., 22: 147-151.

Kotaru, M., Ikeuchi, T. and Yoshikawa, H. 1987. Investigations of Antinutritional Factors of the Winged Bean (Psophocarpus tetragonolobus). Food Chemistry, 24: 279-286.

Manzoor, S., Aslam, I. and Singh, R.D. 2016. Comparative analysis of trypsin inhibitor activity in common pulses and its partial purification. J. Chem. Pharm. Res., 8(8): 382-386

Mendel, F., Carol, E.L., Seung, U., Hyun, J.K., In-Seon, L., Jae-Oke, B. and Nobuyuki, K. 2009. Tomatine containing green tomato extracts inhibit growth of human breast, colon, liver, and stomach cancer cells. J. Agric. Food Chem., 57: 5727-5733.

Noonan, S.C. and Savage, G.P. 1999. Oxalic acid and its effects on humans. Asia pacific Journal of Clinical Nutrition, 8: 64-74.

Pant, G., Panwaar, M.S., Negi, D.S. and Rawat, M.S. 1989. Spermicidal activity of triterpenoid glucosides of Pentapanax leschenaultii., 54: 477.

Price, K.R., Johnson, I.T. and Fenwick, G.R. 1987. The chemistry and biological significance of saponins in foods and feeding stuffs. CRC. Criti. Rev. Food Sci. Nutr., 26: $27-135$
Shukla, P., Kumar, R. and Raib, A.K. 2016. Detection of minerals in green leafy vegetables using laser induced breakdown spectroscopy. Journal of Applied Spectroscopy, 83(5): 872-877.

Sinha, K. and Vikrant, K. 2017. Review on: Antinutritional factors in vegetable crops. The Pharma Innovation Journal, 6(12): 353-358.

Son, Y.O., Kim, J., Lim, J.C., Chung, Y., Chung, G.H and Lee, J.C. 2003. Ripe fruit of Solanum nigrum L. inhibits cell growth and induces apoptosis in MCF-7 cells. Food Chem Toxicol., 41: 1421-1428.

$\mathrm{Su}, \mathrm{H}$. and Guo, R. 1986. Inhibition of acrosine activity of human spermatozoa by saponins of Bulbostermma paniculatum Xtian Yike Daxue Xuebae 7, 225. Chem. Abstr., 1008: 49459.

Toan, N.H. and Preston, T.R. 2019. Taro as a Local Feed Resource for Pigs in Small Scale Household Condition. Available online: http://www.lrrd.org/lrrd22/8/toan22152. htm (accessed on 31 May 2019).

Uusiku, N.P., Oelofse, A. and Duodu, K.G. 2010. Nutritional value of leafy vegetables of sub-Saharan Africa and their potential contribution to human health: A review. Journal of Food Composition and Analysis, 23(6): 499-509.

Zagrobelny, M., Bak, S., Rasmussen, A.V., Jorgensen, B., Naumann, C.M. and Moller, B.L. 2004. Cyanogenic glucosides and plant insect interactions. Phytochemistry, 65: 293- 306 